\title{
Searching for Light-Induced Genes in Hymenopteran Insect - Nasonia vitripennis: Transcription of $13 \%$ of the Genes Is Regulated by Light ${ }^{+}$
}

\author{
Yifan Wang and Roelof Hut
}

Citation: Wang, Y.; Hut, R. Searching for Light-Induced Genes in Hymenopteran Insect - Nasonia vitripennis: Transcription of $13 \%$ of the Genes Is Regulated by Light, in Proceedings of the 1st International Electronic Conference on Entomology, 1-15 July 2021, MDPI: Basel, Switzerland, doi:10.3390/IECE-10536

Published: 1 July 2021

Publisher's Note: MDPI stays neutral with regard to jurisdictional claims in published maps and institutional affiliations.

Copyright: (c) 2021 by the authors. Submitted for possible open access publication under the terms and conditions of the Creative Commons Attribution (CC BY) license (http://creativecommons.org/licenses /by/4.0/).
Groningen Institute for Evolutionary Life Sciences, University of Groningen, The Netherlands

* Correspondence: Yifan.wang@rug.nl

+ Presented at the 1st International Electronic Conference on Entomology (IECE 2021), 1-15 July 2021; Available online: https://iece.sciforum.net/.

Hymenopteran insects, including bees, wasps, and ants, are crucial species of our ecosystems and fulfill valuable ecological roles in nature, as well as in agricultural and industrial activities. With recent reports on dramatic global declines in population size for both bees and wasps, there is an urgent need to understand their circadian system, since it is essential for orientation, foraging, and anticipation of the environment (Eban-Rothschild and Bloch, 2011).

A key component in circadian system regulation is light. In Drosophila, the light input pathway involves the light-sensitive protein - cryptochrome (CRY) by inducing protein degradation (Katz and Minke, 2009). In mammals, a non-light sensitive CRY is present and the light input pathway is through CREB by inducing period (PER) expression (Chauhan et al., 2017). However, for other insect species like hymenopterans, that possess only non-light sensitive CRY, the mechanisms behind circadian light entrainment remain unclear.

We hypothesize that there may be light-driven circadian gene induction in hymenopteran insects, similar to what has been reported for mammals. To investigate this hypothesis, we have subjected Nasonia to different light conditions and conducted an RNAsequencing experiment to identify any light-induced gene expression. Our results provide a better understanding of the molecular mechanisms underlying the circadian light input pathway in hymenopterans as well as insight into the possible disruption of circadian entrainment by artificial light in hymenopteran insects.

\section{References}

1. Chauhan, R., Chen, K., Kent, B. and Crowther, D. (2017). Central and peripheral circadian clocks and their role in Alzheimer's disease. Disease Models \& Mechanisms, 10(10), pp.1187-1199.

2. Eban-Rothschild A., Bloch G. (2012) Circadian Rhythms and Sleep in Honey Bees. In: Galizia C., Eisenhardt D., Giurfa M. (eds) Honeybee Neurobiology and Behavior. Springer, Dordrecht. https://doi.org/10.1007/978-94-007-2099-2_3

3. Katz, B. and Minke, B. (2009). Drosophila Photoreceptors and Signaling Mechanisms. Frontiers in Cellular Neuroscience, 3. 